DOI: 10.5212/UNILETRAS.V.35I1.0008

\title{
Do Schibboleth AO DIGITAL: A PALAVRA NOS ESPAÇOS DE INDETERMINAÇÃO
}

\section{FROM THE Schibboleth UP TO DIGITAL: THE WORD IN THE SPACE OF INDETERMINACY}

\author{
Luís Cláudio Dallier Saldanha*
}

\begin{abstract}
Resumo: Este artigo analisa as relações de indeterminação entre espaços e língua, tendo como pano de fundo os usos do termo schibboleth no contexto da tradição literária judaica e do pensamento germânico-judaico moderno. A partir da obra de Paul Celan, examina-se a palavra nos espaços de fronteira e ambivalência, a fim de se trabalhar a poética do limiar e, num breve excerto, dialogar com o conto "Famigerado", de Guimarães Rosa, e sua forma de lidar com a ambiguidade da palavra. Percorrendo essa trajetória da relação entre literatura e espaços de indeterminação, chega-se ao contexto da linguagem digital para considerar algumas implicações da escrita no ciberespaço.
\end{abstract}

Palavras-chave: Literatura comparada. Paul Celan. Guimarães Rosa. Texto digital.

\begin{abstract}
This article analyzes the relationship of indeterminacy between spaces and language, as background the uses of the term schibboleth within the Jewish literary tradition and German-Jewish modern thought. Starting with Paul Celan's work, which examines the word within border and ambivalence. In order to work with the poetics of threshold, and a brief excerpt, dialogue with the short story " Famigerado ", Guimarães Rosa, and how he deals with word ambiguity. By walking through the history, starting from the relationship of indeterminacy between spaces and language, to the context of the digital language to consider some implications of writing in cyberspace.
\end{abstract}

Keywords: Comparative literature. Paul Celan. Guimarães Rosa. Digital text.

*Doutor em Educação (UFSCar), Mestre em Língua Hebraica e Literatura e Cultura Judaicas (USP) e Graduado em Letras (UERJ). Membro do Grupo de Pesquisa ALPHA (FE/USP) e Coordenador do Grupo de Pesquisa sobre EaD no UniSEB. Email: luisdallier@ig.com.br 
AsPeCTOS SOCIOLINGUísticos DO ÉTIMO HEBRAICO SCHIBBOLETH

O contexto bíblico-judaico é o ponto de partida para o exame de alguns aspectos linguísticos e literários do termo hebraico schibboleth (לתבישיש). A palavra é registrada no Tanakh (Bíblia Hebraica), no Sefer Shoftim (livro de Juízes), quando relata o episódio de uma guerra entre duas tribos de Israel: Efraim e Gileade (BÍBLIA HEBRAICA STUTTGARTENSIA, 1984, p. 424).

Derrotados, os efraimitas fogem por uma região na qual o rio Jordão apresentava trechos rasos que possibilitavam sua travessia a pé. Nesse espaço de fuga, os guerreiros da tribo de Gileade se postam para impedir a debandada dos efraimitas. Dado que eram tribos irmãs, com diversas semelhanças entre si, inclusive falando a mesma língua, ainda que com variações linguísticas, a narrativa bíblica apresenta como estratégia dos gileaditas para identificar os membros da tribo em fuga a imposição de uma senha: pronunciar a palavra schibboleth "corretamente".

Como os efraimitas trocavam a fricativa alveopalatal chiante [S] pela fricativa alveolar sibilante [s] no início da palavra, ficava evidente a identidade dos efraimitas ao pronunciarem ['sibəlk $\theta$ ] no lugar de ['frbalk $\theta$ ], trocando o " $\mathrm{x}$ " pelo "s". Assim, se contrapunha o schibboleth ${ }^{1}$ dos gileaditas ao sibboleth dos efraimitas. $\mathrm{O}$ texto bíblico dá conta de que quarenta e

\footnotetext{
${ }^{1} \mathrm{Na}$ opinião do linguista alemão Christoph Gutknecht (2011), a pronúncia dos gileaditas do som inicial da palavra hebraica schibboleth seria, na verdade, uma fricativa dental surda, como o "th" da língua inglesa.
}

dois mil efraimitas são mortos nos vaus do Jordão, ao pronunciarem a palavra dentro da variedade linguística que os identificava como pertencentes ao "outro" grupo.

O termo que serviu como senha ou "palavra de passagem" nesse espaço de embate e morte é, geralmente, traduzido para o português como "espiga" e "corrente de rio" (BEREZIN, 1995, p. 618), além de "feixe de ramos" e "torrente" (KIRST et al., 1988, p. 243).

De qualquer modo, é possível eleger o sentido de "espiga" para o termo hebraico schibboleth, mas, como lembra Derrida (1986, p. 18), a palavra importa menos pelo seu sentido do que pela maneira como ela é pronunciada. Assim, na apreciação da narrativa bíblica, a ênfase recai sobre o significante, em sua particularidade fonética, com suas implicações sociolinguísticas, sem que com isso se defenda aqui uma dissociação radical do significante de seu significado.

A palavra hebraica schibboleth ganha, assim, uma ressignificação, a partir da narrativa bíblica, ao servir como uma espécie de palavra de passagem que acabará por determinar o destino daqueles que a pronunciam nesse espaço de indeterminação.

É interessante notar que o espaço em que a palavra é pronunciada é um lugar de passagem, de limites, de travessia, pois se trata de trechos do rio Jordão nos quais o ultrapassamento de fronteiras ou de espaços limites é possível. Esse entre-lugar, espaço de transição, se caracteriza pela indeterminação, uma vez que ali se apresenta a dúvida sobre a identidade daqueles que por ele passam ou fogem. O elemento de identidade ou de não identidade se revelará por meio da 
língua, reduzida a uma palavra que marca a variedade linguística entre as tribos irmãs.

Esse episódio da narrativa bíblica, que acaba incorporado à tradição judaico-cristã, torna-se emblemático e significativo no tratamento de questões relacionadas com a violência e a discriminação diante da diferença étnica e cultural marcada ou manifestada linguisticamente.

O termo também é empregado para dar conta de traços ou aspectos linguísticos que são distintivos ou característicos de determinado grupo, sem que haja necessariamente ações de violência ou de preconceitos implicadas. Coulmas (1981 apud DE MORAES, 2008, p. 217), por exemplo, refere-se a uma Schibboleth-Funktion (função schibboleth) que corresponde "a situações em que determinadas fórmulas de rotina são utilizadas para marcar a que grupo social se pertence".

A palavra schibboleth ganha também releituras que estendem seu significado e conceito para aspectos que vão além de questões linguísticas, associando o termo hebraico a elementos de diferenciação, distinção e demarcação de ideias, correntes, culturas e posicionamentos intelectuais.

Aqui, interessa mais uma breve apreciação da apropriação que se faz da palavra schibboleth na esteira do pensamento judaico, particularmente na Europa, no século passado, para analisá-lo como elemento representativo da poética de Paul Celan.

SChibboleth NO CONTEXTO DO PENSAMENTO JUDAICO MODERNO

No contexto do pensamento judaico moderno, o termo hebraico schibboleth comparece em autores diversos, como em Marx (1973, p. 78), que defende o estudo das fontes como o schibboleth da Escola Histórica do Direito; em Buber (1978, p. 76, 81), com o sentido de marco distintivo da identidade e correspondendo ao próprio "eu", pois “a palavra 'eu' é o próprio 'schibboleth' da humanidade”; em Freud (1982; Pfrimmer, 1994), para se referir ao sonho è sexualidade como elemento distintivo da psicanálise; em Derrida (1986, 1987), com o sentido de senha que aponta para a diferença inscrita na língua e no próprio corpo, resultando historicamente em discriminação; e em Celan (1983, 1993), particularmente no poema "Schibboleth", com o sentido de "palavra de passe", conotando passagem para além da fronteira ("ultrapassamento de fronteira") ou a impossibilidade dessa passagem, a interdição, no contexto do horror do Shoah (Holocausto).

Dos autores aqui mencionados, o poeta e tradutor Paul Celan torna-se emblemático porque sua obra representa o movimento de línguas que migram e se movimentam em espaços e vivências marcados pela dor da intolerância para com as diferenças, pela indeterminação diante das fronteiras e pelo movimento de uma poética que se articula entre o calar e o falar.

As tensões entre língua e espaço podem, inicialmente, serem identificadas em Paul Celan na sua opção por escrever em alemão, ainda que ele não fosse alemão e a língua alemã não ter sido a única de sua infância, como destacou Derrida (2001) em determinada ocasião. É pertinente lembrar, também, que Celan não escreveu somente 
em alemão. Filho de judeus pertencentes "à minoria germanófona judaica de Czernowitz (cidade romena, quando ele nasceu em 1920, mas que até 1918 era parte do Império Austro-Húngaro)", Celan vive a experiência de migrar e percorrer lugares diversos, numa confluência de línguas distintas em seus trabalhos de tradução e produção poética, apesar de eleger o alemão como a língua principal de seus poemas (SELIGMANN-SILVA, 2004, p. 150).

Celan escreve a partir de um tempo e lugar marcados pela tensão, pela guerra e pelo caos. Seu lugar é a diáspora e seu tempo é aquele das vivências e memórias dos horrores do Shoah. Sobre ele, já se disse que é "um autor que escreve uma poesia 'de datas': que, benjaminianamente quer dar uma face às datas da sua história” (SELIGMANN-SILVA, 2004, p. 151).

Numa carta em que parece reagir à sentença de Adorno (1962, p. 26) sobre a impossibilidade da poesia ou do lírico após Auschwitz, Celan (apud CANTINHO, 2005) afirma que "não há nada no mundo que possa levar um poeta a deixar de escrever, nem mesmo o fato de ser judeu e o alemão a língua dos seus poemas".

Essa intersecção de espaços na relação com o poético se revela aguda na tematização do Shoah. Para Celan, no contexto do Shoah e de tantas outras situações históricas de destruição, a língua é o bem que não se perde, que permanece, ainda que essa língua se mostre emudecida, atravessando os espaços de horror e morte.

Nesse percurso pelo espaço da dor, do terror e da morte, a língua atravessa o lugar do caos sem dar qualquer "palavra para aquilo que ocorreu", mas essa travessia mostra uma língua que sai, lá na frente, "enriquecida por tudo aquilo" (CELAN, 1983, p. 185). De certo modo, a própria língua se torna um lugar a ser habitado em meio aos espaços inóspitos e hostis.

A hospitalidade da língua é uma imagem significativa porque nas passagens e travessias por espaços de peregrinação e diáspora, a própria língua migra, a própria língua se move, de modo que o forasteiro leva seu país e sua língua; como afirma Celan (apud DERRIDA, 2001), o país migra a todas as partes como a língua.

\section{A poética e o espaço em Paul Celan}

Em Paul Celan, a língua e o poético estão no limiar, no espaço do risco. Para ele, os poemas estão a caminho, em direção a alguma coisa. Nesse sentido, vale a pena considerar a linguagem literária e, particularmente, o poema, a partir da sugestiva imagem oferecida por Celan (1983 apud CANTINHO, 2005), que associa o poema a uma "forma de aparição da linguagem". Assim, o poema seria como "uma garrafa lançada ao mar, abandonada à esperança" e que um dia pode "ser recolhida numa praia, talvez na praia do coração. Também neste sentido os poemas são um caminho: encaminham-se para um destino [...] para um lugar aberto".

O poema está à procura de um lugar porque se move "em direção ao aberto, ao vazio, ao livre", do qual se estálonge, indicando que a poesia "pode significar uma mudança de ar", exatamente porque a poética busca um topos, um lugar (CELAN, 1999, p. 176). 
Celan (1983 apud LINS, 2005, p. 30) confessa que escreveu poemas para se orientar, "para explorar onde estava e aonde deveria ir". Para ele, a poética é uma Toposforshung, a busca ou pesquisa de um topos, de uma "u-topia", tentando "traçar e retraçar limites" (SELIGMANN-SILVA, 2004, p. 150).

Schibboleth é um dos poemas de Celan (1993) em que o tema da passagem, do mover-se entre espaços ou de ser impedido de avançar, aparece de modo emblemático e contundente. Publicado em 1955, faz parte da coletânea intitulada Von Schwelle zu Schwelle (De limiar em limiar), e se revela um poema no qual se está diante do próprio limiar da mudez, em face de uma realidade que parece ser indizível. Mas não só em função do que é tematizado se percebe o limiar ou o espaço de indeterminação no poema. O limiar também está presente no fato de o poema ter sido escrito em alemão e, mesmo assim, ter mantido sem tradução alguns termos ou expressões, como "schibboleth" e "no pasarán”. Conforme observa Nouss (2012, p. 33), “com essas palavras não traduzidas, o leitor permanece de fato no limiar da língua estrangeira. Como Celan o era diante de sua própria língua e de sua própria história”.

Estar no limiar pode implicar a indeterminação diante do dizer e do calar. É interessante notar que no poema "Schibboleth" a referência a espaços diversos remete a experiências e realidades que parecem emudecer e impor o silêncio. Apesar disso, o poema insiste em dizer, em gritar, mesmo diante da dor e dos espaços de indeterminação e opressão. O poema remete ao schibboleth da narrativa bíblica não apenas porque tal palavra comparece em seu título, mas porque alude a situações limites, de indeterminação e de ultrapassamento.

Os espaços e suas (in)determinações no eu-lírico são reveladores no poema. Nos versos "Ruf's, das Schibboleth, hinaus/ In die Fremde der Heimat:/ Februar. No pasarán", tem-se a referência à "Guerra de Espanha, figurada pelas menções ao mês de fevereiro, data da tomada do poder pelos republicanos, e de seu grito de adesão: No pasarán". Também o último verso do poema remete a espaços e eventos históricos de "resistência e revolta contra a opressão na Espanha, França e Áustria, quando a história marca a recusa da passagem, do limiar" (NOUSS, 2012, p. 32-33).

Diante dessas considerações, é preciso questionar o lugar da palavra poética na relação com os espaços que a emudecem e a provocam ao mesmo tempo. Até que ponto a experiência humana, no tempo e no espaço, pode ser vivenciada pela linguagem e pela literatura?

De que modo a palavra pode permanecer diante da experiência que é rememorada, quando essa experiência impõe o silêncio, o emudecimento, a morte?

Como se percebe em Celan (1999, p. 77 apud GINZBURG, 2004, p. 86), a palavra pode não vingar, apesar de ser promessa de brilho, ela pode resultar em cinzas, em apagamento, como nos versos do longo poema Stretto, publicado em seu livro Sprachgitter (CELAN, 1959 apud LINS, 2004, p. 87): "Kam, kam./ Kam ein Wort, kam,/ kam durch die Nacht/wolltleuchten, wolltleuchten/Asche/Asche, Asche".

\footnotetext{
${ }^{2}$ Chama-o, ao Schibboleth, grita-o/ Para a estranheza da pátria:/ Fevereiro. No pasarán . (CELAN, 1993)

${ }^{3}$ Veio, veio/ Veio uma palavra, veio/ veio pela noite,/ queria brilhar, queria brilhar/ Cinzas/ cinzas, cinzas.
} 
Como observa Ginzburg (2004, p. 87), "as cinzas apontam para um lado terrível da experiência histórica, e o gesto de apontar exprime negativamente a intensidade do que não pode ser representado".

A poética de Celan, desse modo, aponta para as tensões e indeterminações provocadas no espaço judaico-germânico, espaço e tempo de ruínas e fragmentação. Nesse espaço em que a hospitalidade se reverte em hostilidade (SELIGMANN-SILVA, 2004, p. 154), permanece o schibboleth: "Alcançável, próximo e não-perdido permaneceu em meio das perdas este único: a língua [...] mas ela teve que atravessar as suas próprias ausências de resposta, atravessar um emudecer, atravessar os milhares de terrores e o discurso que traz a morte" (CELAN, 1983, p. 185 apud SELIGMANN-SILVA, 2004, p. 149).

SCHIBboleth NA LÍNGUA PORTUGUeSA: BREVE EXCERTO EM GUIMARÃES ROSA

Alguns já apontaram que na língua portuguesa o nosso schibboleth corresponderia ao "ão" (RIBEIRO, 2002; DA SILVA, 2008; MORENO, 2008; BIZOCHI, 2009), distinção fonética do português que ofereceria dificuldades quase intransponíveis para ser pronunciada, por estrangeiros, com a nasalidade tão característica daqueles que a têm como língua materna. ${ }^{4}$

\footnotetext{
${ }^{4}$ No contexto brasileiro, há outras referências em estudos linguísticos que dão conta de traços distintivos valendo-se do termo schibboleth, como a menção encontrada em Câmara Jr. (1977, p. 52), que identifica no -s posterior chiante do Rio de Janeiro um schibboleth em relação ao -s anterior sibilante do português de "quase todo o resto Brasil".
}

Esse traço distintivo do português - o "ão" - pode-se entrever no conto "Famigerado", de Guimarães Rosa, de Primeiras estórias (1967), quando o narrador denomina determinado topônimo do sertão como "Serra do São Ão", argumento que Ribeiro (2002) desenvolve com maestria, chamando também a atenção para a presença de um schibboleth na narrativa rosiana ao conferir à palavra "famigerado", ou à própria explicação do significado para "famigerado", o poder de vida e de morte.

Na narrativa rosiana, um jagunço está para matar ou preservar a vida de um moço da cidade que the chamara de "famigerado", dependendo a decisão da explicação que um médico lhe der, explicando se tal termo é uma ofensa ou um louvor.

A pergunta do jagunço sobre os sentidos da palavra "famigerado", e não apenas seu significado denotativo, é como "uma arma carregada de ameaça” (WISNIK, 2002, p. 180). Cabe ao médico, por meio das palavras, desarmar o espírito do jagunço, proeza que o doutor acaba conquistando, valendo-se da ambiguidade do termo "famigerado" e construindo um discurso que escamoteia seus sentidos conotativos e pejorativos. Detendo-se na etimologia da palavra, destaca o sentido de "alguém que tem fama" ou que é célebre. A situação se caracteriza como um verdadeiro impasse, pois o jagunço questiona as explicações do médico, que tem suas palavras como que convertidas numa espécie de schibboleth.

O médico tem consciência do poder de vida ou de morte em suas palavras não apenas em relação ao destino do moço que aplicara 
ao jagunço o adjetivo "famigerado", mas em relação a si mesmo, pois como declara o médico: "Eu não tinha arma ao alcance. Tivesse, também não adiantava. Com um pingo no i, ele me dissolvia" (ROSA, 1962, p. 13).

Deve-se notar que, no caso do schibboleth da narrativa bíblica, a ambivalência na língua reside basicamente no nível do significante, enquanto que na narrativa rosiana a ambiguidade situa-se no significado da palavra que soa desconhecida aos ouvidos do jagunço. Além disso, o conto de Guimarães Rosa se insere no espaço do sertão, de ausência de urbanização e da força da lei do estado. É uma dimensão espacial na qual a carência, a fragilidade e a indeterminação também estão na palavra. $E$ nesse espaço de tensão e de ambivalência em que a palavra joga importante papel, o sentido franco e honesto resulta em guerra, "ao passo que o sentido duplo e matreiro é que produz a paz" (RIBEIRO, 2012, p.317).

Assim como em Celam e no contexto judaico do termo schibboleth, em Rosa a língua aponta para a tensão e a animosidade, conduzindo à suspeição de que "longe de nos unir ela nos põe em conflito" (RIBEIRO, 2012, p.318).

Essa suspeita, para muitos, parece se confirmar nas palavras tecidas e urdidas no ciberespaço. Nesse espaço virtual de desterritorialização e de babelização, a língua teria potencializada sua indeterminação e sua ambivalência, além de assumir formas inéditas em sua instrumentalidade como marca da diferença.

\section{SCHibBoleth NOS ESPAÇOS DigitAIS}

No mundo digital, a ambiguidade da palavra seria levada a paroxismos, sendo portadora tanto de "vida" quanto de "morte", remetendo à própria ambivalência das novas tecnologias, com as tensões entre seu lado "sombrio" e sua face "iluminada" (FEENBERG, 1999).

Assim como o espaço virtual e digital que a palavra habita é marcadamente fluido, indeterminado, caótico, labiríntico e prenhe de possibilidades infinitas, a língua se manifestaria no ciberespaço a partir de sua vocação para o dizer e o silenciar, construir e destruir, juntar e separar, identificar e diferenciar.

Com a digitalização ou a virtualização de suportes materiais, a língua não se limita a formas fixas de escrita ou de oralidade, mas ganha possibilidades de mixagem com outras linguagens e formas expressivas, movendo-se para além da linearidade e da sequencialidade, em redes hipertextuais que se caracterizam pela desterritorialização dos espaços de uso da língua e de produção do texto.

Essa situação não deixa de provocar estranhamentos e preocupações, o que não é incomum, pois ao considerarmos a própria história da linguagem verbal, particularmente no tocante à escrita, as grandes mudanças causaram inquietações importantes. Nesse sentido, é preciso lembrar que, inicialmente, a escrita surge como meio de assegurar a perpetuação no tempo e no espaço da linguagem verbal, estendendo, por exemplo, as ideias ou a obra de um autor para além de seu tempo e espaço ou, dito de outra forma, para além de sua própria vida ou sua própria morte. No Fedro, Platão (1989), por exemplo, trata a escrita como um risco à memória, ao conhecimento e à relação entre o mestre e o discípulo, uma vez que a escrita apartaria o autor de 
seu discurso, marcando uma ausência que comprometeria o entendimento e provocaria uma imprevisibilidade de interpretações.

Nessa separação da escritura em relação a quem escreve, residiria, então, uma primeira dimensão de desterritorialização da língua, pois o texto separaria no tempo e no espaço o autor de suas palavras ou sua escritura. Como afirma Derrida (2003), a escrita se manifestaria como "a separação do corpo do corpus".

No ciberespaço, esse elemento de separação da escritura de seu produtor ganha nova configuração, pois a escrita vai além dos limites da autoria, se coletiviza, incorpora a interatividade e torna o leitor também um cocriador. A abertura e a instabilidade do texto ganham formas inéditas, e seu caráter fragmentário se manifesta nos meios digitais como uma das marcas distintivas.

Interessa também aqui pontuar que o espaço digital no qual a escrita se virtualiza é o espaço de diluição de fronteiras, espaço que também se apresenta como o da democracia virtual e no qual navegam sujeitos que não mais precisariam ter suas produções textuais ou literárias circunscritas a delimitações geográficas, sociais e editoriais.

$\mathrm{Na}$ rede, circulam livremente textos e autores diversos. Ociberespaçocomportariatanto os textos do cânone, da legitimação acadêmica e do mercado editorial quanto os textos portadores de iniciativas e experimentações pessoais e aventureiras. Longe de amarras editoriais e da legitimação dos espaços institucionais, muitos textos seriam marcados por indeterminações identitárias ou determinações espúrias, categorizados como plágio, lendas urbanas ou de "autoria desconhecida".
Nesse mar caótico e hipertextual, muitos enxergam uma democracia e liberdade radicais na produção literária, pois o ciberespaço daria voz e vez a qualquer um que queira publicar seus textos, fazer circular suas produções. Entretanto, a pluralidade e a fragmentação do ciberespaço exigiriam "separar o joio do trigo", identificar a "boa literatura", estabelecer o que possui qualidades estéticas e o que é simplesmente mero exercício libertário da escrita. Nesse sentido, a literatura interviria "dialeticamente como uma alternativa à mera conectividade e ao apagamento da subjetividade nos meios digitais" (SALDANHA, 2008, p.170).

Aqui, então, se interpõe novamente a questão do schibboleth enquanto ultrapassamento de fronteiras, como palavra de passagem que se constitui em senha para outros espaços, pois a profusão de textos na rede exigiria uma senha para fazer parte da chamada "boa literatura".

Mas seria possível pensar em uma univocidade literária? Um consenso para medir o que é ou não "boa literatura"? Qual seria o schibboleth que daria passagem para o mundo literário, para o domínio e espaço dos textos legitimados e identificados com a "boa literatura" no mundo digital? Seria possível falar em critérios de literariedade aplicados à poética digital?

Essas questões não são simples nem comportam respostas definitivas ou unívocas. Sua complexidade se verifica, por exemplo, ao se considerar a atribuição indevida de autoria a textos pretensamente pertencentes à tradição literária e que circulam nas redes sociais. 
É prática comum atribuir a nomes consagrados, como Clarice Lispector, Caio Fernando Abreu, Luís Fernando Veríssimo, Fernando Pessoa, Machado de Assis e outros mais, a autoria de textos que circulam na Internet. Esses casos de falsa autoria não são nenhuma novidade, pois os textos apócrifos têm uma longa tradição. A falsa autoria, porém, assume nas redes sociais um caráter de schibboleth dos tempos digitais, servindo como espécie de senha para que textos de autores desconhecidos e de menor expressividade literária ganhem adesão e circulação impressionante em sites de relacionamento.

Essa circulação anárquica de fragmentos e de textos apócrifos com o apelo indevido da "marca registrada" de grandes autores não deixa de ser surpreendente porque, além de revelar o despertar de um interesse pela poesia, mostra a "própria dissolução do juízo crítico" ao lidar com o repertório literário que circula na Internet (DE PAULA, 2009).

Ao mesmo tempo em que "a poesia é, paradoxalmente, a forma mais recorrente e a mais comentada nos espaços dedicados à literatura na Internet", além dos contos e outros textos curtos, manifesta-se certa caricaturização do poético, pois "para a grande maioria dos leitores permanece a tentação de considerar o poema como exposição espontânea dos sentimentos imediatos do autor, espaço da confissão íntima e da sinceridade do ânimo pungente" (DE PAULA, 2009). Daí que a falsa autoria atribuída aos textos campeões de circulação nas redes sociais acaba sendo uma espécie de schibboleth, uma senha para adentrar no espaço dos repertórios literários consagrados.

\section{ConSIDERAÇões FINAIS}

A questão da falsa autoria nos fragmentos de textos que circulam na Internet e a inédita pluralidade que marca a poética digital indicam as tensões presentes na relação entre a palavra e o ciberespaço, num contexto de indeterminações e de necessidade de senhas ou "palavras de passagem" que garantam, mais do que a conectividade, a sobrevivência ou o estabelecimento num espaço caótico e de fronteiras fluidas.

Ainda que essas tensões e indeterminações do texto digital não se assemelhem aos conflitos da poética de Celan ou à tensão do ambiente ficcional do conto "Famigerado" de Rosa, elas guardam certa proximidade com o contexto discursivo do schibboleth, com os condicionamentos que os espaços exercem na produção da palavra.

Nos espaços de passagem, nos lugares de fronteiras móveis ou no mundo digital, a palavra permanece como abertura, como possibilidade, como senha para transitar no limiar, exercendo sua força de identidade e (in)determinação. Não raro, serve também para excluir, apartar, demarcar espaços.

Assim, não se pode ignorar a "tensão existente na produção textual do ciberespaço, o que leva tanto às possibilidades de construção crítica do conhecimento quanto à reprodução de padrões objetivantes do saber e à reificação do sujeito" (SALDANHA, 2006). Por isso, nesse reino tensionado das palavras, será sempre bem-vinda a capacidade crítica e reflexiva, a capacidade que orienta o mover-se entre o calar e o dizer. 


\section{REFERÊNCIAS}

ADORNO, T. Crítica cultural e sociedade. In: Prismas. Tradução de Augustin Wernet e Jorge Mattos Brito de Almeida. São Paulo: Ática, 1998, p.7-26.

BEREZIN, R. Dicionário hebraico-português. São Paulo: EDUSP, 1995.

\section{BÍBLIA HEBRAICA STUTTGARTENSIA.} 2.ed. Stuttgart: Deutsche Bibelgesellschaft, 1977.

BUBER. M. Eu e tu. São Paulo: Cortez \& Moraes, 1978.

CÂMARA JR., J. M. Para o estudo da fonêmica portuguesa. 2.ed., Rio de Janeiro: Padrão, 1977.

CANTINHO, M. J. A neve das palavras. Espéculo Revista de estudios literarios. Universidad Complutense de Madrid, 2005. Disponível em: http://pendientedemigracion. ucm.es/info/especulo/numerozo/aneve.html Acesso em: 10 abr. 2013.

CARBONI, F. Fala que te direi quem és! Revista espaço acadêmico, ano II, n. 23, abr. 2003. Disponível em http://www.espacoacademico. com.br/023/23ccarboni.htm .

CELAN, P. Der meridian und andere prosa. Frankfurt: Suhrkamp, 1983.

O meridiano In: Cristal. Trad. Claudia Cavalcanti. São Paulo: Iluminuras, 1999.

Schibboleth. Sete rosas mais tarde: antologia poética. Trad. João Barrento e Y. K. Centeno. Lisboa: Cotovia, 1993, p. 64-65.

DA SILVA, D. O xibolete do português. Jornal do Brasil, 25 mar. 2008.

DE MORAES, J. G. M. Fórmulas de rotina: definição, funções e classificação. Pandaemonium germanicum, $\mathrm{n}^{\circ} 12$, 2008, p. 210-220.
DE PAULA, M. F. Entre a falência e a redenção: a polêmica de textos literários na internet. Revista Icarahy, Niterói, n. 1, ago. 2009. Disponível em: http://www.revistaicarahy. uff.br/revista/html/numeros/1/dliteratura/ MARCELO_FERRAZ_DE_PAULA.pdf. Acesso em: 22 maio 2013.

DERRIDA, J, Schibboleth pour Paul Celan. Paris: Ed. Galilée, 1986.

Schibboleth. In: COLIN, A. D. (Org.). Argumentum e silentio: international Paul Celan Symposium. Berlim; Nova Iorque: Walter de Gruyter, 1987. p.16-42.

. La langue n'appartient pas: entretien avec Jacques Derrida. Europe, n.861/862, jan.fev. 2001, p. 81-91.

Chaque fois unique, la fin du monde.

Paris: Galilée, 2003.

FEENBERG, A. Questioning technology. London: Routledge, 1999.

FREUD, S. Contribución a la história del movimiento psicoanalítico. Obras completas. Buenos Aires: Amorrortu, 1982. v. XIV.

GUTKNECHT, C. Codewort schibboleth: Wenn falsche Betonung das Leben kostet. In: Jüdische Allgemeine, Berlim, n. 27, 07 jul. 2011. Disponível em: http://www.juedischeallgemeine.de/article/view/id/10757 Acesso em 20 maio 2013.

KIRST, N. et al. Dicionário hebraicoportuguês \& aramaico-português. São Leopoldo: Sinodal; Petrópolis: Vozes, 1988.

LINS, V. Paul Celan, na quebra do som e da palavra: poesia como lugar de pensamento. In: Poesia e crítica: uns e outros. Rio de Janeiro: 7 Letras, 2005, p. 23-34.

MARX, K. H. Das philosophische Manifest der historischen Rechtsschule. In: Karl Marx \& FriedrichEngelsWerke, v.1. Berlim: Dietz Verlag, 1973. 
MORENO, C. 0 prazer das palavras. Porto Alegre: L\&PM Editores, v.2, 2008, p.13-16.

- Xibolete. Sua língua, 2009. Disponível em http://wp.clicrbs.com.br/ sualingua/2009/10/23/xibolete/

NOUS, A. A tradução: no limiar. ALEA, Rio de Janeiro, vol. 14/1, jan.-jun. 2012. Disponível em: http://www.redalyc.org/ pdf/330/33023299002.pdf. Acesso em: 15 maio 2013. p. 13-34.

PFRIMMER, T. Freud, leitor da Bíblia. Rio de Janeiro: Imago, 1994.

PLATÃO. Fedro. Lisboa: Guimarães Editores, 1989.

ROSA, J. G. Primeiras estórias. Rio de Janeiro: J. Olympio, 1967.

SALDANHA, L. C. D. Literatura e semiformação no ciberespaço. Texto Digital, Florianópolis, ano 2, n. 2, dez. 2006. Disponível em: http://www.periodicos.ufsc.br/index. php/textodigital/article/view/1376/1075 Acesso em 15 mai. 2013.

. Subjetividade e literatura no contexto da educação a distância. In: CORRÊA, Alamir A. (Org.). Ciberespaço: mistificação ou paranoia. Londrina: UEL, 2008.

WISNIK, J. M. Famigerado. Scripta, Belo Horizonte, v. 5, n. 10, p. 177-198, $1^{\circ}$ sem. 2002. Disponível em: http://www.ich.pucminas. br/cespuc/Revistas_Scripta/Scripta1o/ Conteudo/N10_Parteo1_art12.pdf

Recebido para publicação em 28 de maio de 2013 Aceito para publicação em 31 de outubro de 2013 